\title{
Effect of intravenous fluid administration on recovery after running a marathon
}

\author{
A. A. Polak MD, B. van Linge MD, PhD, F. L. P. A. Rutten MD and Th. Stijnen PhD \\ Department of Orthopaedic Surgery, University Hospital Rotterdam, The Netherlands
}

\begin{abstract}
After the Rotterdam Marathon on 21 April 1991 (ambient temperature $5.8^{\circ} \mathrm{C}$, relative humidity $74 \%$, wind velocity $5 \mathrm{~m} \mathrm{~s}^{-1}$ ) data from 66 athletes were analysed for information concerning total recovery and recovery from pain, stiffness, loss of appetite, sleep disturbance and fatigue. The pulse rate, body weight and temperature were measured. The athletes were divided at random into two groups. Thirty-four athletes received an intravenous infusion of 2.51 of a $2.5 \%$ glucose $/ 0.45 \% \mathrm{NaCl}$ solution. Thirty-two athletes received a placebo infusion of $100 \mathrm{ml}$ $0.9 \% \mathrm{NaCl}$. Recovery took 9.2 days in the placebo group and 10.2 days in the infusion group. All athletes had pain and/or stiffness after the marathon. The immediate replacement of 2.51 of fluid had no significant influence on the rate of total recovery, the number of days with pain or stiffness, the appetite, sleep or fatigue. On the first day after the marathon the pulse rate was increased. The rectal temperature was not affected. The athletes were also divided into fast and slow runners without regard to fluid replacement. Fast runners (those running the race in less than $\mathbf{2 h} 55 \mathrm{~min}$ ) needed more time to recover than slower runners and pain and/or stiffness lasted longer in the fast group. Athletes who equalled or improved their best previous result also needed more time to recover than athletes who did not, although there were no significant differences in pain and stiffness. Athletes did not benefit from immediate fluid replacement after running the 1991 Rotterdam Marathon.
\end{abstract}

Keywords: Intravenous infusions, recovery, marathon, athletics

Running a marathon jeopardizes the fluid balance. It also causes a large loss of water and electrolytes ${ }^{1-3}$. Exercise-induced dehydration alters fluid-electrolyte homeostasis, cardiovascular functions and thermal balance. Prolonged exercise also depletes muscle glycogen stores ${ }^{4-8}$. Fluid replacement is essential to restore physical working capacity ${ }^{9}$, beverages usually being taken to accomplish this. Inhibition of gastric emptying after strenuous exercise can prolong the period needed to restore the fluid balance ${ }^{10-12}$. Moreover, usually less fluid is ingested than the amount lost ${ }^{9}$, and drinking does not restore plasma volume within $3 h^{8,9,12}$. The question addressed in

Address for correspondence: Astrid Polak, Department of Orthopaedic Surgery, University Hospital Rotterdam Dijkzigt, Dr Molewaterplein 40, 3015 GD Rotterdam, The Netherlands

(C) 1993 Butterworth-Heinemann Ltd 0306-3674/93/030205-04 this investigation is: does immediate intravenous fluid replacement affect recovery after a marathon race?

A search of the literature showed that there are almost no data available dealing with recovery after a marathon race. Therefore a study was designed to gather information about the recovery of marathon runners and the effect of intravenous fluid infusion immediately following the race.

\section{Subjects and methods}

Our study population was chosen from the list of competitors. Experienced male marathon runners were selected. Only those who had completed a previous marathon in less than $3 \mathrm{~h}$ and were members of a Dutch track and field club were entered in the study. Of the 382 athletes who fulfilled the above requirements 263 were selected because they lived in, or in the vicinity of, Rotterdam, or in one of the other big cities in the Netherlands. These 263 athletes were asked by informative letter to participate in our investigation. We received a positive response from 98 athletes. The athletes were divided at random into two groups. The participants in each group were to receive an i.v. infusion $(100 \mathrm{ml} 0.9 \%$ $\mathrm{NaCl}$ in group 1 and $2.512 .5 \%$ glucose $/ 0.45 \% \mathrm{NaCl}$ in group 2) administered by anaesthetists and their auxiliaries. The infusions were administered to groups 1 and 2 in separate rooms. All athletes had a cooling down period of approximately $30 \mathrm{~min}$. The $100-\mathrm{ml}$ infusion took on average $15 \mathrm{~min}$, whereas the 2.5-1 infusion was completed after about $50 \mathrm{~min}$. Questions concerning recovery, pain, stiffness, loss of appetite, sleep disturbance and fatigue, were answered by the athletes on the 36 days following the marathon by filling in a questionnaire. The questions were answered by using a visual analogue scale of $0-10$. On days $1,3,7,14$ and 21 the athletes were asked to determine their weight, pulse rate and rectal temperature. All athletes received the fullest possible written information about the aims and methods of the investigation. They gave written consent and the protocol of the study was approved by the Medical Ethics Committee of the Medical Faculty and the University Hospital of Rotterdam. On the day of the marathon 17 athletes failed to appear and 11 athletes dropped out of the race before the finish. One athlete was in poor physical condition and on medical grounds he was given the 2.5-l infusion instead of the 
Table 1. Characteristics of the competitors

\begin{tabular}{lll}
\hline & \multicolumn{1}{c}{$\begin{array}{c}\text { Group 1 } \\
(\mathrm{n}=32)\end{array}$} & \multicolumn{1}{c}{$\begin{array}{c}\text { Group 2 } \\
(\mathrm{n}=34)\end{array}$} \\
\hline Age (years) & $37.97(23-52)$ & $38.59(29-58)$ \\
Weight $(\mathrm{kg})$ & $69.58(54-86.5)$ & $68.02(54-79)$ \\
Length $(\mathrm{cm})$ & $179.7(165-193)$ & $177.6(160-187)$ \\
Previous marathon $(n)$ & $9.6(0-49)$ & $6.9(1-30)$ \\
Experience (years) & $7.3(2-25)$ & $8.0(2-25)$ \\
Weekly training sessions & $5.2(4-9)$ & $5.4(3-11)$ \\
Weekly training (km) & $80.4(50-130)$ & $80.7(35-165)$ \\
Best marathon time (min) & $172(147-208)$ & $169(146-182)$ \\
\hline
\end{tabular}

Values are mean (range)

100-ml infusion which was meant for him. This athlete was excluded from the investigation. Three questionnaires were not received. Thus, finally, we were able to analyse the data of 66 athletes using Student's $t$ test. The characteristics of the competitors are given in Table 1. The weather during the marathon was cold and sunny: the ambient temperature was $5.8^{\circ} \mathrm{C}$, the wind velocity $5 \mathrm{~m} \mathrm{~s}^{-1}$, and the relative air humidity $74 \%$.

\section{Recovery}

An athlete was considered to have recovered when the unpleasant after effects of the marathon had disappeared and when he had resumed his normal running activities covering his normal distance. We found no significant difference in the average time needed to recover from running the marathon between group 1 and group 2. Most athletes (83\%) took between 3 and 10 days to recover. Details of recovery are given in Table 2.

A graph of the cumulative percentage of recovered athletes is given in Figure 1.

\section{Pain and stiffness}

The athletes were asked to classify their muscle pain and/or stiffness on a $0-10$ visual analogue scale $(0=$ maximal pain/stiffness, $10=$ no pain/stiffness) during the 36 days following the marathon. There were no significant differences between group 1 and group 2 although group 2 showed a tendency to have longer and more muscle pain and stiffness. The nonsignificant increased stiffness in group 2 (2.5-1 infusion) could be attributed to the longer period of immobilization (50 versus $15 \mathrm{~min}$ ) compared with group 1 (the placebo group). Pain and stiffness lasted on average 3.3 days. Two athletes had an unusually long period of muscle pain (13 and 36 days). This was probably caused by a strain to their calf muscles. The period of pain in the muscles did not exceed 8 days in the other

Table 2. Average number of days to achieve recovery

\begin{tabular}{lrr}
\hline & \multicolumn{1}{c}{ Days } & Marathon time (min) \\
\hline Group 1 $(n=32)$ & $9.2(3-33)$ & \multicolumn{1}{c}{$81(154-234)$} \\
Group 2 $(n=34)$ & $10.2(3-35)$ & $171(147-200)$ \\
\hline
\end{tabular}

Values are mean (range) runners. Six athletes had no muscle pain at all, although they complained of stiffness for 3-5 days. One athlete had stiffness for 30 days, this was caused by a muscle injury (calf). Four athletes had no stiffness at all, but they did have muscle pain (2-5 days). In general, stiffness caused by the marathon lasted 1-7 days. Figure 2 shows the decreasing percentage of athletes having muscle pain in the days following the marathon. Figure 3 shows the average

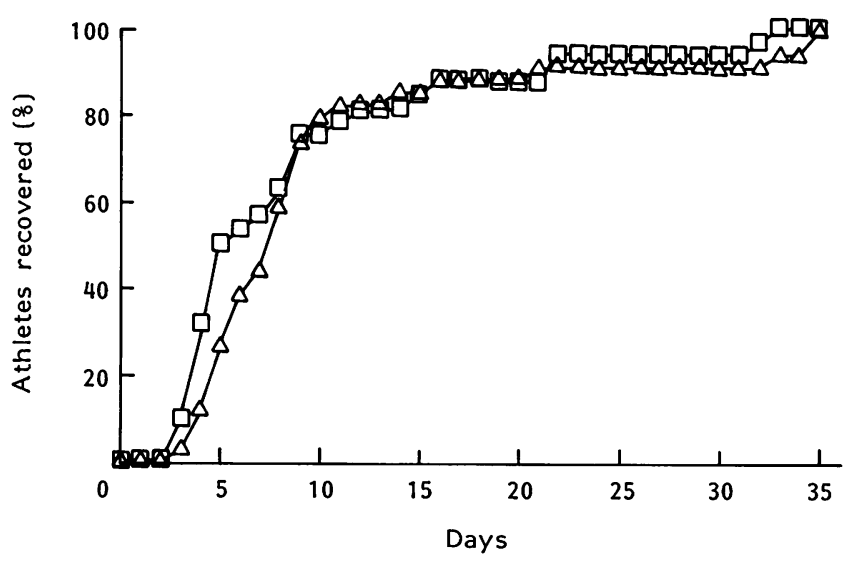

Figure 1. Cumulative percentage of athletes fully recovered after the marathon; $\square$ group $1100 \mathrm{ml}$ i.v.; $\triangle$ group 2 $2500 \mathrm{ml}$ i.v.

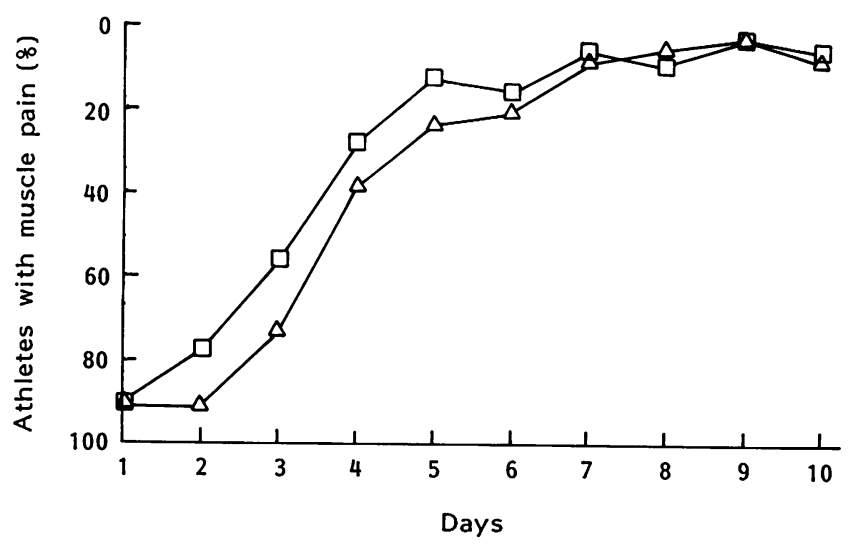

Figure 2. Percentage of athletes having muscle pain after the marathon; $\square$ group $1100 \mathrm{ml} \mathrm{i.v.;} \triangle$ group $22500 \mathrm{ml}$ i.v.

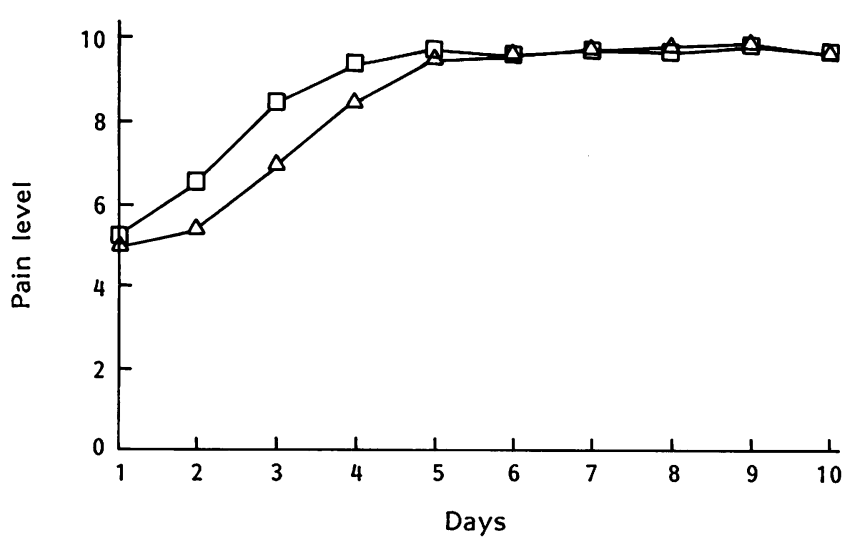

Figure 3. Average level of muscle pain after the marathon. 10 , no muscle pain; 0 , maximal muscle pain; $\square$ group $1 ; \triangle$ group 2 


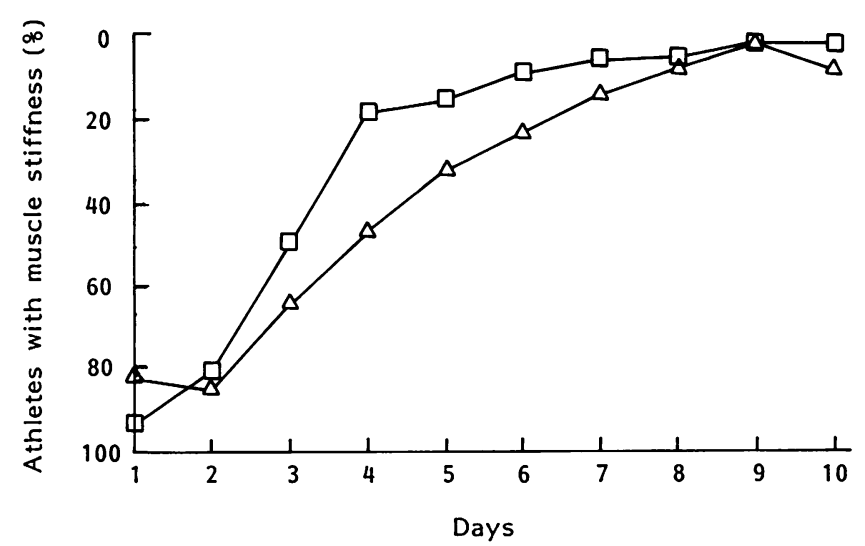

Figure 4. Percentage of athletes having muscle stiffness after the marathon; $\square$ group $1100 \mathrm{ml}$ i.v.; $\triangle$ group 2 $2500 \mathrm{ml}$ i.v.

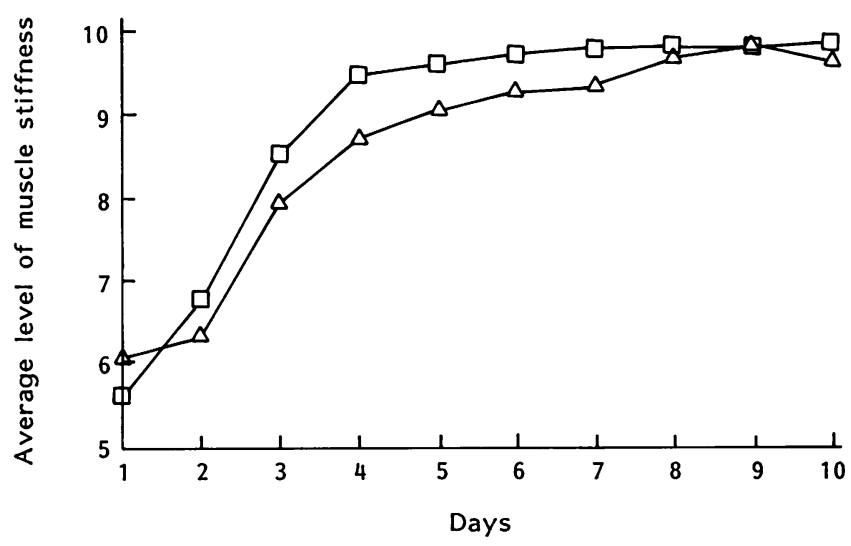

Figure 5. Average level of muscle stiffness after the marathon; 10 , no stiffness; 0 , maximal muscle stiffness; $\square$ group $1100 \mathrm{ml}$ i.v.; $\triangle$ group $22500 \mathrm{ml}$ i.v.

level of muscle pain after the marathon. Figure 4 shows the percentage of athletes experiencing stiffness and Figure 5 the level of stiffness.

\section{Fatigue}

Each athlete had to judge the fatigue he felt during the day and was asked to classify this on a $0-10$ scale. Again there was no significant difference between the two groups. An average of 1.2 days with fatigue was found after the marathon. Half the athletes $(51.5 \%)$ did not feel tired at all. There was a minimum of 1 day and a maximum of 8 days ( 1 athlete) fatigue. Most athletes felt tired from 1 to 3 days after the marathon. Again there was a tendency in group 2 to report tiredness more and of a longer duration than in group 1 . The decreasing percentage of tired athletes and the level of their tiredness is illustrated in Figures 6 and 7.

\section{Appetite}

The athletes were asked to judge their appetite in the 36 days after the marathon. Most runners noticed a decrease in their appetite for the first 3 days after the marathon. No significant differences were found between the groups.

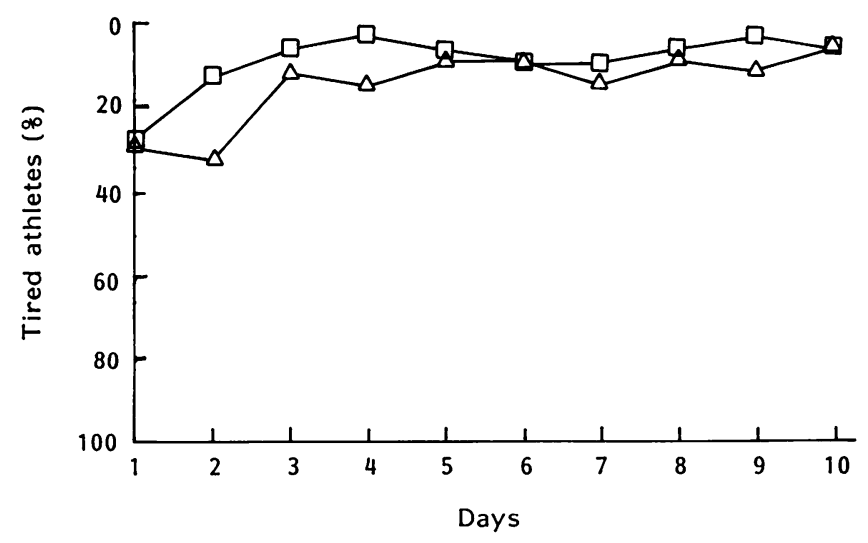

Figure 6. Percentage of athletes feeling tired after the marathon; $\square$ group $1100 \mathrm{ml}$ i.v.; $\triangle$ group $22500 \mathrm{ml}$ i.v.

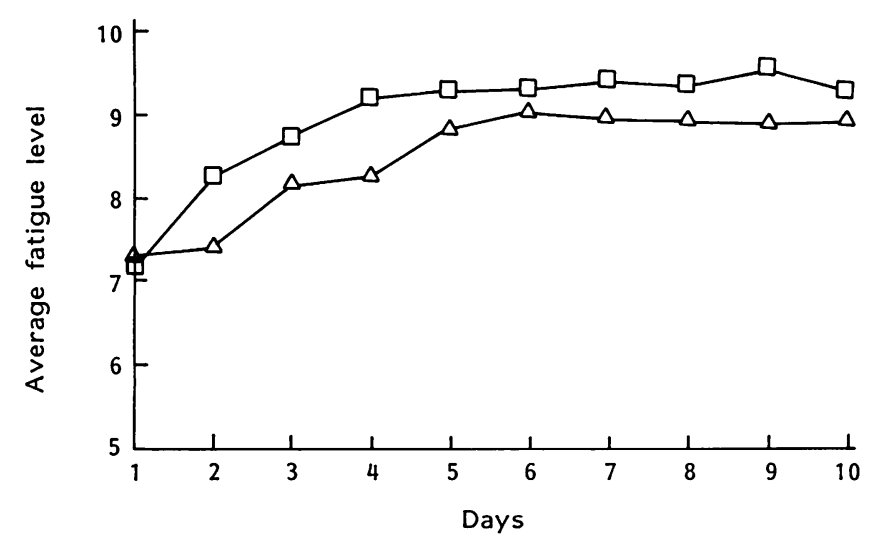

Figure 7. Average level of fatigue after the marathon; 10 , no fatigue; 0 , maximal fatigue; $\square$ group $1100 \mathrm{ml} \mathrm{i.v.;} \triangle$ group $2500 \mathrm{ml}$ i.v.

\section{Sleep}

The athletes were asked if they had unusual difficulty falling asleep and $30 \%$ answered yes after 1 day, falling to $10 \%$ after 2 days. There were no significant differences between the two groups.

\section{Training}

The athletes were asked to report their training sessions and the difficulties they had with their training after the marathon. Thirty athletes resumed their training activities the day after the marathon. The other 36 took 1 or more days off -25 took 1 day off and ten athletes from 2 to 5 days. One athlete did not train for 8 days. When asked if they had more difficulties with their training than usual, most athletes reported having problems for the first 4 days after the marathon (47 athletes). Seventeen athletes had trouble with their training from 5 to 13 days after the marathon. Two athletes needed 20 and 27 days before they could train as usual. None of the athletes runs every day, therefore this number of days cannot be taken as an exact indication for recovery. Nevertheless, none of the athletes considered themselves as recovered until they were capable of training at their original level. 


\section{Pulse rate, body weight and temperature}

All athletes were asked to measure their pulse rate, body weight and temperature on days 1, 3, 7, 14 and 21 after the marathon. Running the marathon did not affect the rectal temperature. There was no difference between groups 1 and 2 . The weight of the athletes in the placebo group (group 1, $100 \mathrm{ml} 0.9 \% \mathrm{NaCl}$ ) rose to normal from day 1 to day 3 . The difference between the two groups was significant $(P<0.001)$. There was no weight change in athletes who received the 2.5-1 infusion. The pulse rate showed a significant elevation on day 1 in comparison with day $3(P<$ $0.001)$. This was the case for both groups. There was no significant difference between the groups. The average pulse rate of the athletes was about 50-52 beats min $^{-1}$. A pulse rate below 50 beats $\min ^{-1}$ was quite common.

\section{Influence of velocity and amount of strain}

Comparing the results of groups 1 and 2 we see that group 2, who received the 2.5-1 infusion, was not doing better than group 1 . On the contrary, group 2 required more time to recover, they had more muscle pain that lasted longer, and they had more stiffness for longer. Although these differences were not significant they were consistent. As can be judged from Table 1 there were no appreciable differences between the two groups before they entered the marathon. However, there was a difference at the finish. Group 2 was faster than group 1. Group 1 reached the finish in an average time of $3 \mathrm{~h} 1 \mathrm{~min}$ (181 min), group $2 \mathrm{had}$ an average time of $2 \mathrm{~h} 52 \mathrm{~min}$ (172 min). This difference was statistically significant $(P=0.015)$. Our findings might suggest that fast athletes need more time to recover and also have more and longer muscle pain and/or stiffness. If we compare the mean best marathon time (the average of the personal best marathon times of the groups) with the time used in this marathon, we find that group 1 performed below their average. Group 2 approached their capabilities more closely. Eight of group 1 improved or ran as fast as their personal best marathon time whereas 19 of group 2 improved or ran as fast as their best time. This suggests that an athlete who makes a greater demand on his resources needs more time to recover and has more and longer muscle problems. To investigate the possible influence of the velocity of the runner we divided the 66 runners into 'slow' and 'fast' groups, regardless of the amount of fluid they received after the marathon. All athletes who ran faster than $2 \mathrm{~h} 55 \mathrm{~min}$ ( $175 \mathrm{~min}$ ) formed group A, all athletes who ran slower than this formed group B. We found that the 'fast' athletes recovered significantly more slowly $P=0.026$ ) and had more $(P=0.030)$ muscle pain than the 'slow' athletes. Group A needed on average 12.5 days to recover, group $B$ needed on average 6.9 days to recover. There was no significant difference in duration of muscle pain, stiffness, fatigue and appetite. To investigate the possible influence of the amount of strain of the runner we divided the 66 runners into a group of athletes who improved or ran as fast as their best time (group $X$ ) and a group of athletes who performed below their capabilities (group $\mathrm{Y}$ ). We found that group $X$ recovered significantly more slowly than group $Y(p=0.013)$. Group $X$ needed on average 12.8 days to recover whereas group $Y$ needed on average 7.4 days. There was no significant difference in muscle pain, stiffness, fatigue, sleep and appetite. We conclude that the velocity of the runner and the amount of strain undergone by the athlete have certain effects on recovery after running a marathon.

\section{Acknowledgements}

The assistance of Maria de Ridder who conducted the statistical analysis is gratefully acknowledged. We thank NPBI Emmer Compascuum, The Netherlands, for offering us the materials needed for the intravenous infusions.

\section{References}

1 Rehrer NJ, Jansen GME, Brouns F, Saris WHM. Fluid intake and gastrointestinal problems in runners competing in a 25-km race and a marathon. Int J Sports Med 1989; 10 (Suppl 1): S22-S25.

2 Armstrong LE, Costill DL, Fink WJ. Influence of diureticinduced dehydration on competitive running performance. Med Sci Sports Exerc 1985; 17: 456-61.

3 Craig FN, Cummings EG. Dehydration and muscular work. J Appl Physiol 1966; 21: 670-4.

4 Carter JE, Gisolfi CV. Fluid replacement during and after exercise in the heat. Med Sci Sports Exerc 1989; 21: 532-9.

5 Adolph EF, Dill DB. Observations on water metabolism in the desert. Am J Physiol 1938; 123: 369-78.

6 Costill DL, Fink WJ. Plasma volume changes following exercise and thermal dehydration. J Appl Physiol 1974; 37: 521-5.

7 Nadel ER, Fortney SM, Wenger CB. Effect of hydration state on circulatory and thermal regulations. J Appl Physiol 1980; 49: 715-21.

8 Nielsen B, Sjogaard G, Ugelvig J, Knudsen B, Dohlmann B. Fluid balance in exercise dehydration and rehydration with different glucose-electrolyte drinks. Eur J Applied Physiol 1986; 55: 318-25.

9 Costill DL, Sparks KE. Rapid fluid replacement following thermal dehydration. J Appl Physiol 1973; 34: 299-303.

10 Riddoch C, Trinick T. Gastrointestinal disturbances in marathon runners. Br J Sports Med 1988; 22: 71-4.

11 Costill DL. Carbohydrate nutrition before, during and after exercise. Fed Proc 1985; 44: 364-8.

12 Brouns F, Saris WHM, Rehrer NJ. Abdominal complaints and gastrointestinal function during longlasting exercise. Int $J$ Sports Med 1987; 8: 175-89. 